\title{
Effects of age and gender on reference levels of biomarkers comprising the pediatric Renal Activity Index for Lupus Nephritis (p-RAIL)
}

Michael R. Bennett ${ }^{1 *} \mathbb{D}$, Qing Ma', Jun Ying ${ }^{2}$, Prasad Devarajan ${ }^{1}$ and Hermine Brunner ${ }^{3}$

\begin{abstract}
Background: Systemic Lupus Erythematosus (SLE) is a multisystem autoimmune disease that disproportionately effects women and children of minorities. Renal involvement (lupus nephritis, or LN) occurs in up to $80 \%$ of children with SLE and is a major determinant of poor prognosis. We have developed a non-invasive pediatric Renal Activity Index for Lupus (p-RAIL) that consists of laboratory measures that reflect histologic LN activity. These markers are neutrophil gelatinase associated lipocalin (NGAL), kidney injury molecule-1 (KIM-1), monocyte chemotactic protein (MCP-1), adiponectin (APN), ceruloplasmin (CP) and hemopexin (HPX). A major gap in the knowledge base and a barrier to clinical utility is how these markers behave in healthy children. We set out to establish a reference range for the p-RAlL markers in a population of healthy children, and to determine if levels of these markers fluctuate with age or gender.
\end{abstract}

Methods: Urine was collected from 368 healthy children presenting to Cincinnati Children's primary care clinic for well child visits and assayed for NGAL, KIM-1, MCP-1, APN, CP and HPX using commercially available kits or assay materials.

Results: Specimens were grouped by age (0-5 years $(n=94) ; 5-10(n=89) ; 10-15(n=93) ; 15-20(n=91))$ and gender $(\mathrm{M}=184, \mathrm{~F}=184)$. For age and gender comparisons, values were log transformed prior to analysis. The medians (minimums, maximums) of each marker in the combined population were as follows: NGAL $6.65(0.004,391.52) \mathrm{ng} / \mathrm{ml}$, KIM-1416.84 (6.22, 2512.43) pg/ml, MCP-1209.36 (9.49, 2237.06) pg/ml, APN 8.05 (0.07, 124.50) ng/ml, CP 465.15 (8.02, 7827.00) ng/ml, HPX $588.70(6.85,17,658.40) \mathrm{ng} / \mathrm{ml}$. All p-RAlL biomarkers but adiponectin had weak but significant positive correlations with age, with NGAL being the strongest $(r=0.33, p<0.001)$. For gender comparisons, NGAL, CP and HPX were elevated in females vs males $(86 \%, p<0.0001 ; 3 \%, p=0.007$, and $5 \%, p=0.0005$ elevation of the log transformed mean, respectively).

Conclusions: We have established a reference range for the p-RAlL biomarkers and have highlighted age and gender differences. This information is essential for rational interpretation of studies and clinical trials utilizing the p-RAlL algorithm.

Keywords: Lupus nephritis, Gender, Reference range, NGAL, Kim-1, MCP-1, Adiponectin, Ceruloplasmin, Hemopexin, Children

\footnotetext{
* Correspondence: Michael.bennett@cchmc.org

'Division Nephrology and Hypertension, Cincinnati Children's Hospital

Medical Center, Cincinnati, OH, USA

Full list of author information is available at the end of the article
} 


\section{Background}

Systemic lupus erythematosus (SLE) is an inflammatory autoimmune disease with multi-organ involvement. Renal involvement in the form of lupus nephritis (LN) is one of the main determining factors in poor prognosis [1]. Childhood-onset SLE (cSLE) [2] typically presents with more severe multi-system disease, including the development of $\mathrm{LN}$ in up to $80 \%$ of patients, a $10-30 \%$ higher proportion than in adult SLE [3-6].

The gold standard of diagnosis of renal involvement in SLE remains histological findings on kidney biopsy [7]. The 3 main patterns of injury used in histological diagnosis and characterization include, mesangial, endothelial and epithelial. These findings are the basis for categorization in the International Society of Nephrology/ Renal Pathology Society (INS/RPS) classification system [8]. Due to invasiveness and cost considerations, it is not often practical to perform serial biopsies to track changes in LN such as worsening disease or response to treatment [9]. As a result, conventional laboratory measures are employed, such as changes in proteinuria, complement levels, and anti-ds DNA levels. These measures are not responsive enough to changes, and cannot differentiate activity from damage. Therefore, they are not well suited to direct treatment [10-12].

In response to the shortcomings of conventional measures, we and others have described novel urinary biomarkers (UBMs) that can assist with LN diagnosis, anticipation of flares, [13-16] and correlate with specific histologic changes associated with LN [17]. We recently developed a Renal Activity Index for Lupus Nephritis (RAIL), which was able to predict LN National Institutes of Health Activity Index (NIH-AI) scores with $>92 \%$ accuracy and tubulointerstitial activity index (TIAI) scores with $>80 \%$ accuracy $[18,19]$. The biomarkers comprising the RAIL include neutrophil-gelatinase associated lipocalin (NGAL), kidney injury molecule 1 (KIM-1), monocyte chemotactic protein 1 (MCP-1), ceruloplasmin $(\mathrm{CP})$, adiponectin (ADP) and hemopexin (HPX). In order to provide greater clinical utility of this panel of markers, we must first understand how these markers behave in healthy individuals, and whether their concentrations change with age or gender. We have previously published reference range and age/gender data for NGAL and KIM-1 [20]. In this study, we set out to establish normative values for MCP-1, CP, ADP and HPX in addition to NGAL and KIM-1 and to determine the effects of age and gender on these normal concentrations.

\section{Methods}

\section{Patients}

This study was approved by the Cincinnati Children's Hospital Medical Center Internal Review Board and was carried out in accordance with the Declaration of
Helsinki. Similar to our previous study [20], samples included were from the Cincinnati Genomic Control Cohort (CGCC). Inclusion criteria were as follows: between 3 years and 18 years of age (prior to 18th birthday) at the time of enrollment, willingness of family to participate and give consent to participate in this project, willingness for participants aged 11 years of age and older to provide assent to participate in this project, ability to complete the introductory medical history, willingness to be contacted annually for future medical history updates, willingness to consent to long-term storage and future analysis of DNA. Subjects were excluded if they met any of the following criteria: presence of known genetic diseases or severe chronic medical conditions, such as chromosomal abnormality, first degree relative participating in the project, unwillingness to complete family and personal health history or allow storage or genetic testing of samples, and adopted, without full contact with biological parent(s) to be able to obtain family history information. Specific exclusion criteria for the subset of patients used in our study was a history of kidney injury or disease, including, but not limited to IGA Nephropathy, kidney stones, abnormal bladder, urinary reflux and ureteral re-implantation.

Recruits were obtained through a marketing plan developed to ensure community based participation, designed with the help of the Clinical Trials Office. Census tract monitoring was used to ensure both the diversity of cohort as well as the representativeness (an equal number of males and females, and approximately $85 \%$ white non-Hispanic, $12 \%$ African-American, and 3\% Asian, Hispanic and other minorities, which represents the population distribution of the 7 counties of Northern Kentucky and Ohio that comprise Greater Cincinnati).

Potential subjects recruited from the community were screened by telephone to ensure eligibility and scheduled for an approximately 2-4 h visit. At this visit, a questionnaire was administered by the clinical research coordinator, a brief physical exam from a licensed physician was performed and samples (blood, urine, hair) were collected. Random urine samples were collected in $4 \mathrm{oz}$ sterile specimen containers. The specimen was then given to the lab 15-60 min after collection, where it was centrifuged briefly to settle particulate matter and aliquoted prior to storage at $-80^{\circ} \mathrm{C}$. Samples were collected from 2007 to 2010 and stored until measurement in 2015. All measurements were performed in one batch in a period of one week.

\section{Biomarker measurements}

The urine NGAL ELISA was performed using a commercially available assay (NGAL ELISA Kit 036; Bioporto, Grusbakken, Denmark) that specifically detects human NGAL [21]. The intra-assay coefficient of variation (CV's) 
was $2.1 \%$ and inter-assay variation was $9.1 \%$. The urine KIM-1 ELISA was constructed using commercially available reagents (Duoset DY1750, R\&D Systems, Minneapolis, MN) as described previously [22]. Intra and interassay CV's for KIM-1 was $2 \%$ and $7.8 \%$, respectively. Adiponectin [CV inter/intra: 4.0\%/9.9\%] was measured using a commercially available ELISA Kit (R\&D Systems, Minneapolis, $\mathrm{MN}$ ); ceruloplasmin [CV inter/intra: 4.1\% /7.1\%] and hemopexin [CV inter/intra: 4.8\%/7.3\%] were also measured by commercially available ELISA kits (Assaypro, St.Charles, MO). MCP-1 was measured by ELISA (R\&D Systems, Minneapolis, MN). Intra and interassay CVs for MCP-1 were $5.0 \%$ and $5.9 \%$, respectively. Urine creatinine measurements were made using an enzymatic assay, and microalbumin (MALB) was measured by immunoturbidimetry, both on a Dimension RXL plus HM Clinical Analyzer (Siemens, Munich, Germany). Coefficients of variability for the creatinine measurements were $2.4 \%$ (intra) and 4.2\% (total), and 2.9\% (intra) and 5.9\% (inter) for MALB.

\section{Statistical analysis}

Means and 95\% confidence intervals were calculated from the non-transformed biomarker values using Sigmaplot 13.0 (Systat Software, Inc., San Jose, CA). All biomarkers showed right skewed in their empirical distributions and were corrected using log transformation before analysis, same methods as showed in other publications [13, 16]. For each biomarker, its means were compared between male and female using a two sample t-test. The relationship between the biomarker and the age was assessed using a Pearson correlation coefficient. In addition, aone-way ANOVA model was performed to test the variations of the biomarker between categorized age groups. For a biomarker that showed associations to both age and gender, we firstly estimated the parameters of intercept and slopes using a linear regression model; and then developed an adjusted biomarker that is invariant to age and gender using the estimates. Considering some of the biomarkers showed a pattern of invert $U$ shape in the initial analysis, we started a model (Model 1) with a $\operatorname{Age}^{2}$ in the independent variable to fit the shape. The model is proposed in the following where $Y$ denotes a predicted value of the biomarker $\mathrm{Y}$ :

$$
\begin{aligned}
Y=a & +b_{1} \times \text { Age }+b_{2} \times \text { Male }+b_{3} \times \text { Age } \\
& \times \text { Male }+b_{4} \times \text { Age } e^{2}+b_{5} \times \text { Age } e^{2} \times \text { Male }
\end{aligned}
$$

Notice Model1 can also be illustrated for male and female respectively in the following:

$$
\hat{Y} \mid \text { Female }=a+b_{1} \times \text { Age }+b_{4} \times A g e^{2}
$$

$$
\hat{Y} \mid \text { Male }=\left(a+b_{2}\right)+\left(b_{1}+b_{3}\right) \times A g e+\left(b_{4}+b_{5}\right) \times A g e^{2}
$$

If both $b_{4}$ and $b_{5}$ are insignificant, we conclude the biomarker is more likely linearly related to Age and the Model1 will be replaced by Model 2 in the following:

$$
\hat{Y}=a+b_{1} \times \text { Age }+b_{2} \times \text { Male }+b_{3} \times \text { Age } \times \text { Male }
$$

Again similarly, the Model 2 can be illustrated for male and female individually in the following:

$$
\begin{aligned}
& \hat{Y} \mid \text { Female }=a+b_{1} \times \text { Age } \\
& \hat{Y} \mid \text { Male }=\left(a+b_{2}\right)+\left(b_{1}+b_{3}\right) \times \text { Age }
\end{aligned}
$$

The Model 2 can be further reduced to Model3 should both $b_{1}$ and $b_{3}$ are insignificant in the estimation.

$$
\hat{Y}=a+b_{1} \times \text { Age }
$$

The age and gender adjusted biomarker $\mathrm{Y}^{*}$ is calculated in the following:

$$
Y^{*}=Y-\hat{Y}
$$

The validation of the adjusted biomarker was performed after randomly stratifying the entire data into two subsets of training data (75\% of the entire data) and testing data (25\% of the entire data). Models (1) and (2) were repeated in the training data to estimate the intercepts and slopes. Then the estimates were used in the testing data to develop the adjusted biomarkers. The adjusted biomarkers were tested of the associations to age and gender using the correlation coefficients, ANOVA models, and t-tests respectively.

All statistical tests were performed using SAS 9.4 software (SAS, Cary, NC). Two-sided $p$-values $<0.05$ were considered statistically significant.

\section{Results}

Urine was collected from 368 children from the Cincinnati Genomic Control Cohort and assayed for NGAL, KIM-1, MCP-1, APN, CP and HPX. Patient demographics can be seen in Table 1 . Specimens were grouped by age $(0-5$ years $(n=94) ; 5-10(n=89) ; 10-15(n=93) ; 15-20(n=91))$ and sex $(M=184, F=184)$. For age and gender comparisons, values were log transformed prior to analysis. The medians (minimums, maximums) of each marker in the combined population were as follows: NGAL 6.65 (0.004, 391.52) ng/ml, KIM-1416.84 (6.22, 2512.43) pg/ml, MCP$1209.36(9.49,2237.06) \quad \mathrm{pg} / \mathrm{ml}, \quad$ APN $8.05 \quad(0.07$, 124.50) ng/ml, CP $465.15(8.02,7827.00) \mathrm{ng} / \mathrm{ml}, \mathrm{HPX}$ $588.70(6.85,17,658.40) \mathrm{ng} / \mathrm{ml}$. 
Table 1 Patient demographics

\begin{tabular}{lllll}
\hline & $3-<5$ years & $5-<10$ years & $10-<15$ years & $15-<18$ years \\
\hline $\mathrm{n}=$ Males/Females & $49 / 45$ & $45 / 44$ & $45 / 48$ & $45 / 46$ \\
Age (mean \pm SE) & $4.04 \pm .06$ & $7.4 \pm .15$ & $12.4 \pm .15$ & $16.3 \pm .1$ \\
Height (cm) & $103.6 \pm .65$ & $124.1 \pm 1.4$ & $155.4 \pm 1.1$ & $170.4 \pm .95$ \\
Height z score & $0.46 \pm .97$ & $0.19 \pm 1.1$ & $0.37 \pm 0.98$ & $0.36 \pm 0.96$ \\
Weight (kg) & $17.7 \pm .35$ & $26.9 \pm .82$ & $50.5 \pm 1.4$ & $67.1 \pm 1.7$ \\
Weight z score & $0.54 \pm 1.1$ & $0.36 \pm .98$ & $0.58 \pm .96$ & $0.57 \pm .99$ \\
BMl & $16.4 \pm .2$ & $18 \pm 1.1$ & $20.7 \pm .42$ & $23.1 \pm .55$ \\
BMl z score & $0.42 \pm 1.2$ & $0.40 \pm .94$ & $0.55 \pm .87$ & $0.39 \pm 1.0$ \\
Race \% & & & & 80.6 \\
- White & 86.2 & 86.5 & 17.2 & 2.6 \\
- Black & 12.7 & 13.5 & 2.2 & 2.2 \\
- Hispanic & 1.1 & 0 & & 2.2 \\
\hline
\end{tabular}

z-scores for height weight and BMI were calculated using published CDC growth charts. [42]

In order to determine if there were gender differences between the RAIL biomarkers, raw values were log transformed (natural log) and subjected to a 2-way Student's t-test. Results can be seen in Table 2. As reported previously [20], NGAL was significantly higher in females than in males (2.52 vs $1.3, p=0.0001)$. HPX and $\mathrm{CP}$ were also higher in females than males (6.58 vs 6.26, $p=0.0005 ; 5.98$ vs. $6.16, p=0.007$, respectively). These results indicate a need to adjust these markers based on gender.

To analyze the effects of age on biomarker levels, we subjected the natural log of the means in each age grouping to an ANOVA model and F-test of variance. Results can be seen in Table 3. To summarize, all biomarkers except HPX had a significant association with age, though not always in a predictable direction. Only NGAL, KIM-1 and MCP-1 steadily increased with each age group. While this indicates that age needs to be taken into account when adjusting the RAIL biomarkers clinically, individual ages may need to be taken into account as opposed to simple groupings. To investigate further, Pearson's tests of correlation was performed between the natural log of biomarker values and the real age (continuous variable) of the subjects (Table 4). NGAL had the strongest positive correlation with age $(r=0.33 ; p<0.0001)$. All other markers had weak positive correlations with age $(r=0.12-0.13)$, except LFABP and Adiponectin, which both had weak negative correlations with age $(r=-0.10, p=0.05 ; r=-0.12, p=0.04$, respectively).

Due to statistically significant associations between the RAIL biomarkers and both gender and age, we developed a method for adjusting the levels for males and females as a function of real age (continuous variable). These parameters can be seen in Table 5 . For biomarkers of KIM-1, NGAL, MCP-1, HPX, and MALB, their slopes of $\mathrm{Age}^{2}$ (or Age $\mathrm{x}$ Age) were not significant in either gender. Hence Model 2 fit better for these markers. For the rest of biomarkers of $\mathrm{CP}, \mathrm{ADP}$ and Creatinine, their slopes of $\mathrm{Age}^{2}$ were significant in boys and hence Model1 was preferred for these biomarkers. To illustrate how we calculate an adjusted biomarker, we use KIM-1

Table 2 Biomarker vs. sex

\begin{tabular}{|c|c|c|c|c|c|c|c|c|c|}
\hline \multirow[t]{2}{*}{ Variable } & \multicolumn{4}{|c|}{ Male } & \multicolumn{4}{|c|}{ Female } & \multirow[b]{2}{*}{$p$-value } \\
\hline & $\bar{N}$ & Mean & SD & Upper limit $^{\mathrm{a}}$ & $\bar{N}$ & Mean & SD & Upper limit $^{\mathrm{a}}$ & \\
\hline KIM-1 (pg/ml) & 183 & 5.90 & 1.00 & 7.90 & 183 & 5.87 & 0.95 & 7.77 & 0.801 \\
\hline NGAL (ng/ml) & 184 & 1.35 & 1.21 & 3.77 & 183 & 2.52 & 1.20 & 4.92 & 0.0001 \\
\hline MCP-1 (pg/ml) & 182 & 5.28 & 0.98 & 7.24 & 178 & 5.14 & 0.97 & 7.08 & 0.162 \\
\hline HPX (ng/ml) & 184 & 6.26 & 0.91 & 8.08 & 182 & 6.58 & 0.86 & 8.30 & 0.0005 \\
\hline $\mathrm{CP}(\mathrm{ng} / \mathrm{ml})$ & 184 & 5.98 & 0.70 & 7.38 & 182 & 6.16 & 0.56 & 7.28 & 0.007 \\
\hline ADP (ng/ml) & 132 & 1.85 & 1.44 & 4.73 & 163 & 1.92 & 0.84 & 3.60 & 0.579 \\
\hline Creatinine (mg/dl) & 184 & 4.70 & 0.78 & 6.34 & 183 & 4.60 & 0.71 & 6.02 & 0.196 \\
\hline MALB (mg/l) & 184 & 2.42 & 0.99 & 4.40 & 182 & 2.57 & 1.03 & 4.63 & 0.174 \\
\hline
\end{tabular}

a Upper limit of normal $=$ mean +2 SD

- All values are natural log 
Table 3 Biomarker vs. age group

\begin{tabular}{|c|c|c|c|c|c|c|c|c|c|c|c|c|c|}
\hline \multirow[t]{2}{*}{ Variable } & \multicolumn{3}{|c|}{ Age $=3-<5$ years } & \multicolumn{3}{|c|}{ Age $=5-<10$ years } & \multicolumn{3}{|c|}{ Age $=10-<15$ years } & \multicolumn{3}{|c|}{ Age $=15-<18$ years } & \multirow[t]{2}{*}{$p$-value of $\mathrm{F}$} \\
\hline & $\mathrm{N}$ & Mean & SD & $\mathrm{N}$ & Mean & SD & $\mathrm{N}$ & Mean & SD & $\mathrm{N}$ & Mean & SD & \\
\hline KIM-1 (pg/ml) & 92 & 5.68 & 1.01 & 90 & 5.78 & 0.97 & 92 & 5.94 & 0.91 & 92 & 6.15 & 0.97 & 0.008 \\
\hline NGAL (ng/ml) & 93 & 1.42 & 1.47 & 90 & 1.63 & 1.30 & 92 & 2.08 & 1.17 & 92 & 2.59 & 1.08 & 0.0001 \\
\hline MCP-1 (pg/ml) & 88 & 5.00 & 0.92 & 89 & 5.11 & 0.97 & 92 & 5.27 & 0.98 & 91 & 5.45 & 1.00 & 0.012 \\
\hline HPX (ng/ml) & 92 & 6.23 & 0.75 & 90 & 6.40 & 0.65 & 92 & 6.56 & 0.85 & 92 & 6.48 & 1.22 & 0.082 \\
\hline $\mathrm{CP}(\mathrm{ng} / \mathrm{ml})$ & 92 & 5.77 & 0.76 & 90 & 6.17 & 0.47 & 92 & 6.20 & 0.61 & 92 & 6.14 & 0.59 & 0.0001 \\
\hline ADP $(n g / m l)$ & 77 & 1.95 & 0.98 & 71 & 2.10 & 0.94 & 82 & 1.96 & 0.98 & 65 & 1.50 & 1.58 & 0.014 \\
\hline Creatinine (mg/dl) & 93 & 4.19 & 0.77 & 90 & 4.48 & 0.64 & 92 & 4.86 & 0.59 & 92 & 5.07 & 0.66 & 0.0001 \\
\hline MALB (mg/l) & 92 & 2.20 & 0.73 & 90 & 2.32 & 0.72 & 92 & 2.72 & 1.09 & 92 & 2.73 & 1.28 & 0.0001 \\
\hline
\end{tabular}

-All values are natural log

as an example for a boy, aged 10 years. Table 5 shows Model 2 is preferred in prediction. The predicted KIM-1 level for this boy will be $5.42+(0.05 \times 10)=5.97$. To return this natural $\log$ to a raw value: exp. $(5.97)=391.5 \mathrm{pg} / \mathrm{ml}$. This formula would differ with the same KIM-1 level if the patient were female. With a female patient: $5.42+(0.03 \times 10)=5.72$. To return the natural $\log$ to a raw value: exp. $(5.72)=304.9 \mathrm{pg} / \mathrm{ml}$.

\section{Discussion}

We set out in this manuscript to describe the normative values of the novel urinary biomarkers we established as a pediatric Renal Activity Index for Lupus Nephritis (pRAIL) $[18,19]$. We also wanted to determine whether gender and age affected the normative values of these markers. While we and others have reported on reference ranges for urine NGAL and KIM-1 [20, 22-25], this is to our knowledge, the first study to establish urinary reference ranges for MCP-1, ADP, CP and HPX. The need for reference values is important for establishing this panel, not only in children, but adults as well [26].

Most studies investigating biomarkers in lupus nephritis and other chronic conditions use disease controls, such as juvenile idiopathic arthritis (JIA) or SLE patients without renal involvement [13,27, 28]. Normal behavior of proteins in the healthy population is an important

Table 4 Biomarker correlation with real age (continuous variable)

\begin{tabular}{lll}
\hline Variable & Pearson's r & $p$-value \\
\hline KIM-1 $(\mathrm{pg} / \mathrm{ml})$ & 0.18 & 0.0004 \\
NGAL $(\mathrm{ng} / \mathrm{ml})$ & 0.33 & 0.0001 \\
MCP-1 $(\mathrm{pg} / \mathrm{ml})$ & 0.19 & 0.0003 \\
HPX $(\mathrm{ng} / \mathrm{ml})$ & 0.12 & 0.018 \\
CP $(\mathrm{ng} / \mathrm{ml})$ & 0.19 & 0.0003 \\
ADP $(\mathrm{ng} / \mathrm{ml})$ & -0.12 & 0.0420 \\
Creatinine $(\mathrm{mg} / \mathrm{dl})$ & 0.47 & 0.0001 \\
MALB $(\mathrm{mg} / \mathrm{l})$ & 0.23 & 0.0001 \\
\hline
\end{tabular}

-Values calculated fromthe natural log of the biomarkers and real age metric in establishing the clinical utility of laboratory tests. Just as proteins will present variability between relatively similar individuals, normal groupings by age and gender often exhibit greater variability and must be taken into account when establishing clinical diagnostic algorithms [20]. In particular, urine proteins have been shown to differ to a greater degree between males and females than in other body fluids, such as cerebrospinal fluid [29].

In this study, we took advantage of the availability of a large cohort of healthy pediatric patients, namely the Cincinnati Genomic Control Cohort. The goal of the development of the cohort was to obtain a population representative sample which could be utilized as controls for a diverse set of projects. Our results showed

Table 5 Parameters used for adjusting biomarkers

\begin{tabular}{|c|c|c|c|c|c|}
\hline \multirow[t]{2}{*}{ BMK } & \multirow[t]{2}{*}{ Parameter } & \multicolumn{2}{|l|}{ Male } & \multicolumn{2}{|l|}{ Female } \\
\hline & & Estimate & StdErr & Estimate & StdErr \\
\hline \multirow[t]{2}{*}{ KIM-1 (pg/ml) } & Intercept & 5.42 & 0.16 & 5.61 & 0.16 \\
\hline & Slope & 0.05 & 0.01 & 0.03 & 0.01 \\
\hline \multirow[t]{2}{*}{ NGAL (ng/ml) } & Intercept & 0.17 & 0.19 & 1.91 & 0.19 \\
\hline & Slope & 0.12 & 0.02 & 0.06 & 0.02 \\
\hline \multirow[t]{2}{*}{ MCP-1 (pg/ml) } & Intercept & 4.77 & 0.17 & 4.87 & 0.17 \\
\hline & Slope & 0.05 & 0.01 & 0.03 & 0.01 \\
\hline \multirow[t]{2}{*}{$\operatorname{HPX}(\mathrm{ng} / \mathrm{ml})$} & Intercept & 6.03 & 0.15 & 6.36 & 0.15 \\
\hline & Slope & 0.02 & 0.01 & 0.02 & 0.01 \\
\hline \multirow[t]{2}{*}{ CP (ng/ml) } & Intercept & 5.18 & 0.10 & 6.47 & 0.10 \\
\hline & Slope & 0.08 & 0.01 & -0.03 & 0.01 \\
\hline \multirow[t]{2}{*}{ ADP (ng/ml) } & Intercept & 2.31 & 0.23 & 2.07 & 0.20 \\
\hline & Slope & -0.05 & 0.02 & -0.01 & 0.02 \\
\hline \multirow[t]{2}{*}{ Creatinine (mg/dl) } & Intercept & 3.78 & 0.11 & 4.05 & 0.11 \\
\hline & Slope & 0.09 & 0.01 & 0.05 & 0.01 \\
\hline \multirow[t]{2}{*}{ MALB (mg/l) } & Intercept & 1.78 & 0.17 & 2.26 & 0.17 \\
\hline & Slope & 0.06 & 0.02 & 0.03 & 0.02 \\
\hline
\end{tabular}

-Values are natural log 
significant associations of our biomarkers with both age and gender. In concordance with our earlier studies and with published literature, NGAL was significantly higher in females than in males in both pediatric and adult populations [20, 24, 25, 30, 31]. HPX was also found to be significantly higher in females. This has not, to the best of our knowledge, been previously reported. HPX is the primary binder of free heme in the blood. Adult females naturally have lower hemoglobin and associated blood levels of heme due to menstruation, which results in lower HPX levels. In the kidneys, HPX is produced primarily in the renal cortex in the setting of nephrotoxic insults, and acts to protect the tubules from free heme radicals $[19,32]$. The reason urine HPX would be elevated in healthy pediatric females would be speculation at this time.

Urine levels of $\mathrm{CP}$ were also found to be higher in females. It has been long known that serum levels of $\mathrm{CP}$, a carrier of copper in the blood, are higher in healthy adult females than males and has also been found to increase in older women [33]. While we found an association with age and ceruloplasmin in the pediatric population, it was more of an inverted $U$ shaped association, increasing from age $3-<5$ up to $10-<15$, but then decreasing in our oldest grouping, $15-<18$. In urine, $\mathrm{CP}$ increased in response to infections, acting as a molecular source of copper which can inhibit bacterial growth [34]. CP is also a ferroxidase, which can transform ferrous iron, which is toxic to renal tubules, to its nontoxic ferric state. While speculative, $\mathrm{CP}$ may be naturally upregulated in females as a host defense due to their greater incidence of UTI compared to males [35].

All of the RAIL proteins showed associations with age, except hemopexin. It is important to note, however, that only NGAL, KIM-1 and MCP-1 had direct positive correlations with age. We have previously shown NGAL and KIM-1 to increase as a function of age [20]. While serum MCP-1 increases with aging in adults, and increases with risk of cardiovascular disease [36], increases in urine MCP-1 in developing children have not been reported to our knowledge. MCP-1 is expressed at high levels in the tubular epithelium with oxidative stress [37] and is predictive of LN flares and LN severity [14, 38]. It would be plausible that there are small increases in subclinical oxidative stress due to environmental exposures in a developing child/adolescent that could potentially lead to increases in tubular expression of MCP-1 in a healthy individual.

"Normalizing" the data for hydration status with urine using creatinine represents a difficult position with a maturing pediatric population. In the growing child, urine creatinine increases as a function of age and maturity [39]. Therefore any "correction" for creatinine applied to our biomarker levels would nullify any increase as a function of age. Indeed, in our population, using a Spearman correlation, urine creatinine demonstrated a significant positive correlation with age $(r=0.54, p<0.001)$. Also, since the pRAIL proteins do not all have a direct positive correlation with age, creatinine normalization would present additional problems. Since creatinine is dependent upon age in this population, it would not be useful as a normalization tool. It would be important to note that not only does creatinine have an intrinsic relationship with age, it also displays a significant relationship with gender. It is well known that creatinine is higher in males, especially after puberty, than females $[40,41]$. As a result, creatinine correction would amplify the difference between males and females in terms of biomarker levels.

The strengths of our study include a large representative healthy pediatric population and established laboratory expertise with the specific methodology used in the study $[18,19]$. This study is not without its weaknesses. Our study is from a single center cohort that is representative of the population of a mid-size US city (Cincinnati, Ohio). Demographics from this cohort would differ from other regions and as a result, our results may not be generalizable to the global population. For instance, $85 \%$ of our study population classified as White/Non-Hispanic, leaving numbers too small to study race as a variable. Also, while our assays are well established, none of them are standardized assays available on a clinical platform for measurement in urine. As a result, our results may vary from those utilizing different assays. Since the cohort was not originally designed for renal or lupus research, certain pertinent data such as glomerular filtration rate, are not available for these patients. It may be interesting in future studies to investigate other variables, such as hemoglobin levels, which could potentially account for underlying differences between HPX levels in males vs. females.

\section{Conclusions}

Our previous work has demonstrated the utility of the RAIL biomarkers to monitor LN activity in both the pediatric and adult population $[18,19]$. The current manuscript has elucidated specific gender and age related associations of the RAIL biomarkers in a population of healthy children. These results have enabled us to develop a method to adjust the levels of the biomarkers for individual patients based on age and sex, to increase the accuracy of our RAIL algorithm. These improvements will increase the clinical utility of the RAIL algorithm and may lead to more effective and personalized treatments for patients with lupus nephritis.

\section{Abbreviations}

ADP: Adiponectin; CP: Ceruloplasmin; HPX: Hemopexin; KIM-1: Kidney injury molecule - 1; LN: Lupus nephritis; MALB: Microalbumin; MCP-1: Monocyte chemotactic protein; NGAL: Neutrophil gelatinase-associated lipocalin; pRAIL: Pediatric renal activity index for lupus nephritis 


\section{Acknowledgements}

The Authors would like to thank Christopher Haffner, MS, MBA for his help with laboratory measurements.

\section{Funding}

Funding for this project was provided by NIH P50 DK096418 to HB and PD. This research was supported in part by the Cincinnati Children's Research Foundation and its Cincinnati Genomic Control Cohort.

\section{Availability of data and materials}

Please contact author for data requests.

\section{Authors' contributions}

MB - study design, data collection, statistical analysis, result interpretation and manuscript preparation; QM - data collection, manuscript preparation; JY - statistical analysis, manuscript preparation; PD and HB- study design, result interpretation, manuscript preparation. All authors read and approved the final manuscript.

\section{Ethics approval and consent to participate}

This study was approved by the Cincinnati Children's Hospital Medical Center Internal Review Board and was carried out in accordance with the Declaration of Helsinki. Families gave consent for their children to participate, and children 11 years of age and older gave assent to participate.

\section{Consent for publication}

Not applicable.

\section{Competing interests}

$\mathrm{PD}, \mathrm{HB}$ and $\mathrm{MB}$ have patent applications regarding the use of the RAIL panel as a diagnostic tool.

\section{Publisher's Note}

Springer Nature remains neutral with regard to jurisdictional claims in published maps and institutional affiliations.

\section{Author details}

'Division Nephrology and Hypertension, Cincinnati Children's Hospital Medical Center, Cincinnati, OH, USA. 'Environmental Health, University of Cincinnati College of Medicine, Cincinnati, OH, USA. ${ }^{3}$ Rheumatology, Cincinnati Children's Hospital Medical Center, Cincinnati, OH, USA.

\section{Received: 28 June 2017 Accepted: 5 October 2017}

\section{Published online: 13 October 2017}

\section{References}

1. Faurschou M, Starklint $H$, Halberg P, Jacobsen S. Prognostic factors in lupus nephritis: diagnostic and therapeutic delay increases the risk of terminal renal failure. J Rheumatol. 2006:33:1563-9.

2. Silva CA, Avcin T, Brunner HI. Taxonomy for systemic lupus erythematosus with onset before adulthood. Arthritis Care Res (Hoboken). 2012;64:1787-93.

3. Livingston B, Bonner A, Pope J. Differences in clinical manifestations between childhood-onset lupus and adult-onset lupus: a meta-analysis. Lupus. 2011:20:1345-55.

4. Hiraki LT, Feldman CH, Liu J, Alarcon GS, Fischer MA, Winkelmayer WC, Costenbader $\mathrm{KH}$. Prevalence, incidence, and demographics of systemic lupus erythematosus and lupus nephritis from 2000 to 2004 among children in the US Medicaid beneficiary population. Arthritis Rheum. 2012;64:2669-76.

5. Wenderfer SE, Ruth NM, Brunner HI. Advances in the care of children with lupus nephritis. Pediatr Res. 2017;81:406-14.

6. Mina R, Brunner HI. Update on differences between childhood-onset and adult-onset systemic lupus erythematosus. Arthritis Res Ther. 2013;15:218.

7. Hagelberg S, Lee Y, Bargman J, Mah G, Schneider R, Laskin C, Eddy A, Gladman D, Urowitz M, Hebert D, Silverman E. Longterm followup of childhood lupus nephritis. J Rheumatol. 2002;29:2635-42.

8. Weening JJ, D'Agati VD, Schwartz MM, Seshan SV, Alpers CE, Appel GB, Balow JE, Bruijn JA, Cook T, Ferrario F, et al. The classification of glomerulonephritis in systemic lupus erythematosus revisited. Kidney Int. 2004;65:521-30.
9. Greloni G, Scolnik M, Marin J, Lancioni E, Quiroz C, Zacariaz J, De la Iglesia Niveyro P, Christiansen S, Pierangelo MA, Varela CF, et al. Value of repeat biopsy in lupus nephritis flares. Lupus Sci Med. 2014;1:e000004.

10. Bennett M, Brunner HI. Biomarkers and updates on pediatrics lupus nephritis. Rheum Dis Clin N Am. 2013;39:833-53.

11. Soliman S, Mohan C: Lupus nephritis biomarkers. Clin Immunol. 2016.

12. Smith EM, Beresford MW. Urinary biomarkers in childhood lupus nephritis. Clin Immunol. 2016

13. Hinze $\mathrm{CH}$, Suzuki M, Klein-Gitelman M, Passo MH, Olson J, Singer NG, Haines KA, Onel K, O'Neil K, Silverman ED, et al. Neutrophil gelatinase-associated lipocalin is a predictor of the course of global and renal childhood-onset systemic lupus erythematosus disease activity. Arthritis Rheum. 2009:60:2772-81.

14. Rovin BH, Song H, Birmingham DJ, Hebert LA, CY Y, Nagaraja HN. Urine chemokines as biomarkers of human systemic lupus erythematosus activity. J Am Soc Nephrol. 2005;16:467-73.

15. Brunner HI, Mueller M, Rutherford C, Passo MH, Witte D, Grom A, Mishra J, Devarajan P. Urinary neutrophil gelatinase-associated lipocalin as a biomarker of nephritis in childhood-onset systemic lupus erythematosus. Arthritis Rheum. 2006;54:2577-84.

16. Suzuki M, Wiers KM, Klein-Gitelman MS, Haines KA, Olson J, Onel KB, O'Neil $\mathrm{K}$, Passo MH, Singer NG, Tucker L, et al. Neutrophil gelatinase-associated lipocalin as a biomarker of disease activity in pediatric lupus nephritis. Pediatr Nephrol. 2008;23:403-12.

17. Brunner Hl, Bennett MR, Mina R, Suzuki M, Petri M, Kiani AN, Pendl J, Witte D, Ying J, Rovin BH, Devarajan P. Association of noninvasively measured renal protein biomarkers with histologic features of lupus nephritis. Arthritis Rheum. 2012;64:2687-97.

18. Gulati G, Bennett MR, Abulaban K, Song H, Zhang X, Ma Q, Brodsky SV, Nadasdy T, Haffner C, Wiley K, et al. Prospective validation of a novel renal activity index of lupus nephritis. Lupus 2017;26(9):927-36.

19. Brunner HI, Bennett MR, Abulaban K, Klein-Gitelman MS, O'Neil KM, Tucker L, Ardoin SP, Rouster-Stevens KA, Onel KB, Singer NG, et al. Development of a novel renal activity index of lupus nephritis in children and young adults. Arthritis Care Res (Hoboken). 2016;68:1003-11.

20. Bennett MR, Nehus E, Haffner C, Ma Q, Devarajan P. Pediatric reference ranges for acute kidney injury biomarkers. Pediatr Nephrol. 2015;30:677-85.

21. Bennett M, Dent CL, Ma Q, Dastrala S, Grenier F, Workman R, Syed H, Ali S, Barasch J, Devarajan P. Urine NGAL predicts severity of acute kidney injury after cardiac surgery: a prospective study. Clin J Am Soc Nephrol. 2008;3:665-73.

22. Chaturvedi S, Farmer T, Kapke GF. Assay validation for KIM-1: human urinary renal dysfunction biomarker. Int J Biol Sci. 2009;5:128-34.

23. Cangemi G, Storti S, Cantinotti M, Fortunato A, Emdin M, Bruschettini M, Bugnone D, Melioli G, Clerico A. Reference values for urinary neutrophil gelatinase-associated lipocalin (NGAL) in pediatric age measured with a fully automated chemiluminescent platform. Clin Chem Lab Med. 2013:51:1101-5.

24. Cullen MR, Murray PT, Fitzgibbon MC. Establishment of a reference interval for urinary neutrophil gelatinase-associated lipocalin. Ann Clin Biochem. 2012;49:190-3.

25. McWilliam SJ, Antoine DJ, Sabbisetti $V$, Pearce RE, Jorgensen AL, Lin $Y$, Leeder JS, Bonventre JV, Smyth RL, Pirmohamed M. Reference intervals for urinary renal injury biomarkers KIM-1 and NGAL in healthy children. Biomark Med. 2014:1-9.

26. Gulati G AK, Ying J, Zhang X, Song H, Ma Q, Haffner C, Wiley K, Bennett M, Rovin $\mathrm{BH}$, Brunner HI. Validating the RAlL Algorithm in Adult Lupus Nephritis Patients [abstract]. Arthritis Rheumatol. 2015;67.

27. Suzuki M, Ross GF, Wiers K, Nelson S, Bennett M, Passo MH, Devarajan P, Brunner HI. Identification of a urinary proteomic signature for lupus nephritis in children. Pediatr Nephrol. 2007;22:2047-57.

28. Suzuki M, Wiers K, Brooks EB, Greis KD, Haines K, Klein-Gitelman MS, Olson J, Onel K, O'Neil KM, Silverman ED, et al. Initial validation of a novel protein biomarker panel for active pediatric lupus nephritis. Pediatr Res. 2009;65:530-6.

29. Guo Z, Zhang Y, Zou L, Wang D, Shao C, Wang Y, Sun W, Zhang L. A proteomic analysis of individual and gender variations in normal human urine and cerebrospinal fluid using iTRAQ quantification. PLoS One. 2015;10:e0133270.

30. Schinstock CA, Semret MH, Wagner SJ, Borland TM, Bryant SC, Kashani KB, Larson TS, Lieske JC. Urinalysis is more specific and urinary neutrophil gelatinase-associated lipocalin is more sensitive for early detection of acute kidney injury. Nephrol Dial Transplant. 2013;28:1175-85. 
31. Kaufeld JK, Gwinner W, Scheffner I, Haller HG, Schiffer M. Urinary NGAL ratio is not a sensitive biomarker for monitoring acute tubular injury in kidney transplant patients: NGAL and ATI in renal transplant patients. Journal of Transplantation. 2012;2012:8

32. Varghese SA, Powell TB, Budisavljevic MN, Oates JC, Raymond JR, Almeida JS, Arthur JM. Urine biomarkers predict the cause of glomerular disease. J Am Soc Nephrol. 2007;18:913-22.

33. Denko CW, Gabriel P. Age and sex related levels of albumin, ceruloplasmin, alpha 1 antitrypsin, alpha 1 acid glycoprotein, and transferrin. Ann Clin Lab Sci. 1981;11:63-8.

34. Hyre AN, Kavanagh K, Kock ND, Donati GL, Subashchandrabose S. Copper Is a Host Effector Mobilized to Urine during Urinary Tract Infection To Impair Bacterial Colonization. Infect Immun. 2017;85(3).

35. Lo DS, Shieh HH, Ragazzi SL, Koch VH, Martinez MB, Gilio AE. Communityacquired urinary tract infection: age and gender-dependent etiology. J Bras Nefrol. 2013;35:93-8.

36. Inadera H, Egashira $\mathrm{K}$, Takemoto M, Ouchi $\mathrm{Y}$, Matsushima $\mathrm{K}$. Increase in circulating levels of monocyte chemoattractant protein-1 with aging. Interf Cytokine Res. 1999;19:1179-82.

37. Mezzano SA, Droguett MA, Burgos ME, Ardiles LG, Aros CA, Caorsi I, Egido J. Overexpression of chemokines, fibrogenic cytokines, and myofibroblasts in human membranous nephropathy. Kidney Int. 2000;57:147-58.

38. Zhang X, Nagaraja HN, Nadasdy T, Song H, McKinley A, Prosek J, Kamadana $\mathrm{S}$, Rovin $\mathrm{BH}$. A composite urine biomarker reflects interstitial inflammation in lupus nephritis kidney biopsies. Kidney Int. 2012;81:401-6.

39. Barr DB, Wilder LC, Caudill SP, Gonzalez AJ, Needham LL, Pirkle JL. Urinary creatinine concentrations in the U.S. population: implications for urinary biologic monitoring measurements. Environ Health Perspect. 2005;113:192-200.

40. Neal RC, Ferdinand KC, Ycas J, Miller E. Relationship of ethnic origin, gender, and age to blood creatine kinase levels. Am J Med. 2009;122:73-8.

41. George MD, McGill NK, Baker JF. Creatine kinase in the U.S. population: impact of demographics, comorbidities, and body composition on the normal range. Medicine (Baltimore). 2016;95:e4344.

42. Kuczmarski RJ, Ogden CL, Guo SS, Grummer-Strawn LM, Flegal KM, Mei Z, Wei R, Curtin LR, Roche AF, Johnson CL. 2000 CDC growth charts for the United States: methods and development. Vital Health Stat. 2002;1 1:1-190.

\section{Submit your next manuscript to BioMed Central and we will help you at every step:}

- We accept pre-submission inquiries

- Our selector tool helps you to find the most relevant journal

- We provide round the clock customer support

- Convenient online submission

- Thorough peer review

- Inclusion in PubMed and all major indexing services

- Maximum visibility for your research

Submit your manuscript at www.biomedcentral.com/submit

) Biomed Central 